\title{
Thermal Degradation of Polyethylene Bags and Millet Stalks: Influence of the Temperature and the Local Concentration of Oxygen on the Conversion Rate of Carbon
}

\author{
Salifou K. Ouiminga ${ }^{1 *}$, Thomas Rogaume ${ }^{2}$, Tizane Daho ${ }^{1}$, Franck Richard ${ }^{2}$, Jean Koulidiati ${ }^{1}$ \\ ${ }^{1}$ Laboratoire de Physique et Chimie de l'Environnement, Université de Ouagadougou, Ouaga, Burkina Faso \\ ${ }^{2}$ Institut Pprime, Département Fluide, Thermique, Combustion, ENSMA —-Téléport 2, Poitiers, France \\ Email: "salifou_ouiminga@univ-ouaga.bf, salif0477@yahoo.com
}

Received November 4, 2011; revised December 12, 2011; accepted December 24, 2011

\begin{abstract}
This paper concerns the influence of temperature and local concentration of oxygen on the conversion efficiency of carbon into $\mathrm{CO}, \mathrm{CO}_{2}, \mathrm{CH}_{4}, \mathrm{C}_{3} \mathrm{H}_{8}, \mathrm{C}_{2} \mathrm{H}_{4}, \mathrm{C}_{2} \mathrm{H}_{2}, \mathrm{C}_{2} \mathrm{H}_{6}, \mathrm{C}_{6} \mathrm{H}_{6}$, during the thermal degradation of plastic bags and millet stalks. The experimental device used is the tubular kiln, coupled to an analyzer Fourier Transform Infrared (FTIR) and a Non Dispersive Infrared analyzer (NDIR). Temperatures are considered between $800^{\circ} \mathrm{C}$ and $1000^{\circ} \mathrm{C}$. Local concentrations of oxygen during thermal degradation are $0 \%, 10 \%$ and $21 \%$. On the one hand results obtained on the influence of temperature show that for each type of thermal degradation and whatever the temperature of the combustion, the rate of conversion of carbon remains substantially the same. In the case of plastic bags, the rate of carbon converted during pyrolysis is about $90 \%$ of carbon converted during reductive combustion. On the other hand, with millet stalks, the carbon converted represents only $60 \%$ of the rate of carbon converted during combustion to $10 \%$ oxygen. $1 \%$ to $2 \%$ of carbon not analyzed is in the form of aromatic compounds that are found most often in the soot and/or tar from this combustion system. Moreover, whatever the temperature, the overall efficiency of carbon conversion increases linearly with the local concentration of oxygen. During the thermal degradation of plastic bags, we see that the reducer environment has fostered the conversion of $7 \%$ of carbon more while the presence of oxygen in double proportion promotes the conversion of $27 \%$ carbon. Regarding the influence of the local content of oxygen, it is clear that for plastic bags, the reactions of oxidation of $\mathrm{CO}$ into $\mathrm{CO}_{2}$ tend to be favored for the benefit of those of hydrocarbons into $\mathrm{CO}$. The formation of $\mathrm{CO}$ and $\mathrm{CO}_{2}$ by oxidation of light hydrocarbons is primarily from gaseous compounds $\mathrm{CH}_{4}$ and $\mathrm{C}_{2} \mathrm{H}_{4}$. At $950^{\circ} \mathrm{C}$, we have also acetylene $\left(\mathrm{C}_{2} \mathrm{H}_{2}\right)$ which is involved in the production of carbon oxides. At $1000^{\circ} \mathrm{C}$, benzene $\left(\mathrm{C}_{6} \mathrm{H}_{6}\right)$ heavily involved in the formation of $\mathrm{CO}$ and $\mathrm{CO}_{2}$. However, with millet stalks, more the local content of oxygen increases, more combustion is better, that is to say that the oxidation reactions producing $\mathrm{CO}_{2}$ are faster than the oxidation reactions of hydrocarbons into $\mathrm{CO}$. The rate of carbon converted into $\mathrm{CO}$ and $\mathrm{CO}_{2}$ is higher for millet stalks than for plastic bags, due to this oxygen levels higher in millet stalks than in plastic bags. Similarly, for the millet stalks, from pyrolysis to combustion (at $10 \%$ and $21 \%$ oxygen), there is practically no hydrocarbon emitted.
\end{abstract}

Keywords: Carbon; Oxygen; Pyrolysis; Combustion; Conversion Rate

\section{Introduction}

In Africa, the production of waste has become a major concern in recent years, especially with the population boom recorded in most medium and large cities. Indeed, the population growth causes an increase in the amount of waste produced. Moreover, with the evolution of science, coupled with the need for man to improve his well being, new products have been placed available to people. Among these products, we cite plastic and especially the

${ }^{*}$ Corresponding author. plastic bags made from polyethylene. The use of this type of plastic bags-not biodegradable-causes a significant increase of plastic waste. Their recycling is not always easy or profitable, they are found in significant quantities in landfills and in the streets, generating strong health and environmental impacts. Thus, the use of plastic bags in Polyethylene (PE) as supplementary fuel in the pottery is an option. One of the most fuels used in the pottery is the stalk of millet. The coupling "plastic bags millet stalks", in combustion, would reduce the amount of millet stalks to use, especially since this fuel is also 
used in animal husbandry (nutrition for animals) and agriculture (for the manufacture of compost). But combustion systems must be adequate, that is to say they must respect standards of quality, safety and environment. It is therefore essential to conduct research to know how behaves the fuel during combustion in similar conditions to those of the pottery. Thus, our investigations have concerned the study of the influence of two experimental parameters (temperature and local oxygen concentration) on the conversion efficiency of carbon during the thermal degradation of plastic bags made from polyethylene and millet stalks. We study three types of thermal degradation: pyrolysis ( $0 \%$ oxygen), the reductive combustion (10\% oxygen) and the oxidant combustion (21\% oxygen). These three types of degradation will allow to follow the evolution of conversion efficiency and a comparison of differents conversion rates. Temperatures are considered between $800^{\circ} \mathrm{C}$ and $1000^{\circ} \mathrm{C}$. The study of the influence of parameters such as temperature and local oxygen concentration, are necessary for optimizing the thermal degradation. In effect, [1-4] show that these parameters strongly influence the thermal degradation of solids.

Work is carried out using the tubular reactor under conditions similar to those encountered in the pottery. The reactor is connected to gas analyzers: Fourier Transform infrared spectrometer (FTIR) and an analyzer with a non-dispersive infrared cell and a paramagnetic cell. The gaseous carbonaceous species analyzed are $\mathrm{CO}, \mathrm{CO}_{2}$, $\mathrm{CH}_{4}, \mathrm{C}_{2} \mathrm{H}_{2}, \mathrm{C}_{2} \mathrm{H}_{4}, \mathrm{C}_{2} \mathrm{H}_{6}, \mathrm{C}_{3} \mathrm{H}_{8}$ and $\mathrm{C}_{6} \mathrm{H}_{6}$.

\section{Properties of Fuels}

An elementary analysis of millet stalks and polyethylene bags, was performed to accurately characterize our fuel and carry out material balances. To do this, samples of each component were analyzed for the determination of the majoritary elements i.e.: $\mathrm{C}, \mathrm{H}, \mathrm{O}, \mathrm{N}, \mathrm{S}, \mathrm{Cl}, \mathrm{H}_{2} \mathrm{O}$ and ashes. These tests have been carried out by the analysis of the National Center for Scientific Research (CNRS) with 5 different samples of each fuel. The values presented in Table 1 correspond to the average of rate from 5 analysis by fuel.

The polyethylene bags are made from PE granules, but during the manufacturing process, some molecules can be added to modify the physical properties of the bags. Thus, we have made in the Table 2, a comparison of elementary analysis $\mathrm{f}$ the polyethylene bags and the pure polyethylene, [5-8].

In view of this review, we find that the polyethylene bags have a chemical composition different from that observed with the pure polyethylene. The differences are mainly at the level of carbon, oxygen, chlorine and ash. These differences are related to the addition of adjuvant.

Similarly, the stalks of millet being biomass predomi- nantly composed of cellulose, it is interesting to characterize this fuel by comparing, in Table 3, its elemental composition to that of fir wood, described by $[1,9,10]$. It appears that the elemental composition of millet stalks is very close to that of wood.

\section{Description of Experimental Apparatus}

The device used is the tubular reactor instrumented to

Table 1. Elementary composition of fuels of the study.

\begin{tabular}{ccc}
\hline Elements & Millet stalks & Polyethylene bags \\
\hline Carbon (C) & $44.4 \%$ & $73.8 \%$ \\
Hydrogen (H) & $6 \%$ & $11.5 \%$ \\
Nitrogen (N) & $0.3 \%$ & $0.2 \%$ \\
Sulphur (S) & $0.15 \%$ & $0.2 \%$ \\
Oxygen (O) & $43.8 \%$ & $4.8 \%$ \\
Chlorine (Cl) & $814 \mathrm{ppm}$ & $300 \mathrm{ppm}$ \\
Water ( $\left.\mathrm{H}_{2} \mathrm{O}\right)$ & $4.4 \%$ & $2.5 \%$ \\
Ashes & $0.8 \%$ & $6.7 \%$ \\
\hline
\end{tabular}

Table 2. Elementary composition of the polyethylene films and pure polyethylene.

\begin{tabular}{ccc}
\hline Elements & Polyethylene bags & Pure Polyethylene \\
\hline Carbon $(\mathrm{C})$ & $73.8 \%$ & $85.4 \%-86.4 \%$ \\
Hydrogen $(\mathrm{H})$ & $11.5 \%$ & $13.5 \%-14.3 \%$ \\
Nitrogen (N) & $0.2 \%$ & $0 \%$ \\
Sulphur (S) & $0.2 \%$ & $0 \%-0.08 \%$ \\
Oxygen (O) & $4.8 \%$ & $0 \%-0.2 \%$ \\
Chlorine (Cl) & $300 \mathrm{ppm}$ & $0 \mathrm{ppm}$ \\
Water $\left(\mathrm{H}_{2} \mathrm{O}\right)$ & $2.5 \%$ & - \\
Ashes & $6.7 \%$ & $0 \%$ \\
\hline
\end{tabular}

Table 3. Elementary chemical composition of the wood and the millet stalks.

\begin{tabular}{ccccc}
\hline Elements & Dumont T. & Beaumont O. & Rogaume T. & Millet stalks \\
\hline Carbon (C) & $49.5 \%$ & $50.9 \%$ & $47.6 \%$ & $44.4 \%$ \\
Hydrogen (H) & $6 \%$ & $5.76 \%$ & $6.4 \%$ & $6 \%$ \\
Nitrogen (N) & $0.5 \%$ & $0.2 \%$ & $0.2 \%$ & $0.3 \%$ \\
Sulphur (S) & - & $0.04 \%$ & $0.2 \%$ & $0.15 \%$ \\
Oxygen (O) & $43 \%$ & $42.1 \%$ & $45.3 \%$ & $43.8 \%$ \\
Ashes & $1 \%$ & $1 \%$ & - & $0.8 \%$ \\
\hline
\end{tabular}


study the thermal degradation of solid materials in pyrolysis and combustion. This device was used to determine for different temperatures, the composition of the volatile gases generated by fast pyrolysis.

Figure 1 presents a diagram of the tubular reactor used.

The central part of the diagram consists of the tubular kiln and the quartz reactor. The kiln is placed horizontally and measure $88 \mathrm{~cm}$ long. It is connected to an automatic temperature control (heat resistance) with $1250^{\circ} \mathrm{C}$ like maximum instruction. The quartz reactor with a total length of $120 \mathrm{~cm}$ and an inside diameter of $7 \mathrm{~cm}$, is partly placed inside the kiln. A thermocouple of type $K$ is placed at its center in order to know the temperature. A basket sample holder (in quartz) is used for the introduction of the fuel inside the kiln.

The flow of oxidizer (nitrogen, "nitrogen + air" or air, depending on the chosen degradation) is performed by a digital control box (ELECTRONIC CONTROLLER 0154) linked to a mass flowmeter of brand BROOKS, type $5850 \mathrm{E}$ that allows a maximum flow gas of $30 \mathrm{Nl} \cdot \mathrm{mn}^{-1}$ with a precision of $10^{-1} \mathrm{Nl} \cdot \mathrm{mn}^{-1}$. A fraction of gas from the degradation is directly collected in a Kevlar bag with a capacity of 37 liters. The volume of gas collected is calculated by the flow of gas carried and the time of filling the bag. Before each filling, the bag is cleaned and the vacuum is made by aspiration with a pump. The gas collected is then taken continuously with a pump and sent to the gas analyzer with a flow rate of $2 \mathrm{Nl} \cdot \mathrm{mn}^{-1}$. These gases pass through a filter that removes soot and tars. Then they cross a box, by Pelletier effect, which removes water vapor before analysis.

The gases collected in the bag are spread into series toward two types of analyzers

- Infrared Non Dispersive (IRND) and paramagnetic analyzers, of brand Servomex, to measure the concentrations of $\mathrm{CO}, \mathrm{CO}_{2}, \mathrm{O}_{2}, \mathrm{SO}_{2}$, and $\mathrm{NO}$;

- Fourier Transform Infrared spectrometer (FTIR) brand Thermo Optek NICOLET, type AVATAR, to determine the concentrations of $\mathrm{CO}, \mathrm{CO}_{2}, \mathrm{CH}_{4}, \mathrm{C}_{2} \mathrm{H}_{2}$,
$\mathrm{C}_{2} \mathrm{H}_{4}, \mathrm{C}_{2} \mathrm{H}_{6}, \mathrm{C}_{3} \mathrm{H}_{8}, \mathrm{C}_{6} \mathrm{H}_{6}$ and $\mathrm{NH}_{3}, \mathrm{HCN}, \mathrm{NO}, \mathrm{NO}_{2}$, $\mathrm{N}_{2} \mathrm{O}$ and $\mathrm{SO}_{2}$.

\section{Experimental Conditions}

The Millet stalks are cut into thin sticks $1.5 \mathrm{~cm}$ long and the polyethylene bags into square sheets of $1.5 \mathrm{~cm}$ of side with less of $1 \mathrm{~mm}$ thick. Samples, with a mass of $500 \mathrm{mg}$, were then weighed with a precision balance, $10^{-2} \mathrm{mg}$. These sizes and these masses allow to avoid the effect of temperature gradient at the degradation of the fuel. This physical phenomenon influences the mode of degradation. Indeed, the degradation of a "fuel thermally thick" would imply the presence of a temperature gradient, while that of a "fuel thermally thin" would be no temperature gradient since in this case the temperature is supposed uniform throughout the solid.

The temperature of preheating of the kiln is programmed to the desired value. The flow of gas is selected to have a fixed residence times. It is based on the residence time of hot gas and the local temperature of degradation. Once the set temperature is reached and stable, the oxidizing gas flow is set. The flow of oxidizing gas is performed by a digital control box, brand ELECTRONIC CONTROLLER, type 0154, connected to a mass flowmeter brand BROOKS, type $5850 \mathrm{E}$, which allows a maximum flow of gas $30 \mathrm{Nl} \cdot \mathrm{mn}^{-1}$ with accuracy to $10^{-1}$ $\mathrm{Nl} \cdot \mathrm{mn}^{-1}$.

Then, the sample is introduced in the kiln with a basket quartz sample holder. The basket is manually entered into the kiln at a constant speed. It is at the center of the kiln, where the temperature is given by a thermocouple of type $\mathrm{K}$. The gases from the decomposition are transported to the gas analyzer. Before each new test, the basket is beforehand removed from the kiln. The response time of the analyzer Fourier Transform Infrared (FTIR) and the analyzers SERVOMEX are high (respectively 40 and 30 seconds), the gases from the thermal degradation are stored in a bag of Kevlar of 37 liters of

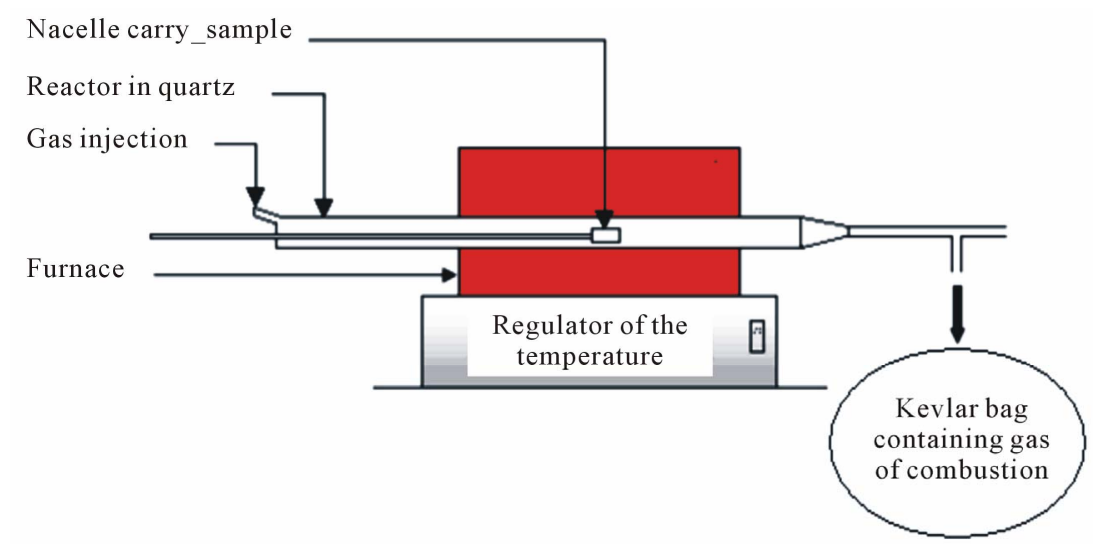

Figure 1. Device of tubular reactor. 
capacity. In other words, flow and pressure of gas leaving the reactor are very high for the analyzers which save different concentrations of the gaseous species. The gases collected are then continuously taken with a pump (with a rate of $2 \mathrm{Nl} \cdot \mathrm{mn}^{-1}$ ) and sent to the gas analyzers. These gases pass through a filter that removes soot and tars in order to prevent their deposit on cells and/or on other internal components of the analyzers. These deposits can damage the components. The transfer lines of gases, the reactor to the bag and the bag to the analyzers are cleaned (by blowing) after each test, to remove residues of soot and tar. The bag for the collection of the thermal degradation gases is changed every five trials, this will prevent deposits of tar, soot and/or particles that can compromise the reliability of the results by reacting with the gases. The results are treated by computer in real time.

The Table 4 shows the various conditions for which the tests were doing.

Our temperature conditions correspond to those used in the thermal degradation of cellulosic and plastic materials, [1,11-16]. The residence time of gases in the hot zone of the reactor was chosen so that the airflow is not too important: given the mass of each sample, a flow too high would imply an only partial degradation of fuel. Indeed, an air flow promotes a very significant cooling of the reaction fuel and a residence time of hot gas too short, and this would cause a decrease in temperature of degradation and an incomplete degradation of fuel.

\section{Results}

\subsection{Carbon Conversion: Influence of Temperature}

The assessments of overall yields of conversion of carbon (in \%) during the thermal degradation of plastic bags made from polyethylene, and millet stalks, are presented in Figures 2 and 3.

From the different assessments made, we find that for each type of thermal degradation and whatever the temperature of combustion, the conversion rate of carbon remains substantially the same. On the one hand the case of plastic bags, the rate of carbon converted during pyrolysis is about $90 \%$ of carbon converted during reductive combustion. On the other hand, with millet stalks, the carbon converted represents only $60 \%$ of the rate of carbon converted during combustion to $10 \%$ oxygen. This difference may be explained by the fact that:

- Plastic bags are mainly made of polyethylene. Polyethylene is a polymer composed of a long chain of monomers. This monomer is ethylene formula $\mathrm{C}_{2} \mathrm{H}_{4}$. Therefore, polyethylene is a polymer consisting essentially single bonds $\mathrm{C}-\mathrm{C}$ and $\mathrm{C}-\mathrm{H}$.

- Millet stalks, in turn, are composed largely of cellulose, hemicellulose and lignin. These three components have chemical formulas formed of polycyclic aromatic compounds.

During pyrolysis, the temperatures can reach a binding energy sufficient to break the single bonds $\mathrm{C}-\mathrm{C}$ and

Table 4. Conditions of thermal degradation tests.

\begin{tabular}{|c|c|c|c|c|c|}
\hline Type of dégradation & Carrier gas & Sample mass (mg) & Temperatures $\left({ }^{\circ} \mathrm{C}\right)$ & Flow of carrier gas $(\mathrm{Nl} / \mathrm{min})$ & Residence time (s) \\
\hline & & & 800 & 11.2 & \\
\hline & & & 850 & 10.7 & \\
\hline \multirow[t]{5}{*}{ Pyrolysis } & Nitrogen & 500 & 900 & 10.2 & 2 \\
\hline & & & 950 & 9.8 & \\
\hline & & & 1000 & 9.4 & \\
\hline & & & 800 & 11.2 & \\
\hline & & & 850 & 10.7 & \\
\hline \multirow[t]{5}{*}{ Combustion (10\%) } & Air + Nitrogen & 500 & 900 & 10.2 & 2 \\
\hline & & & 950 & 9.8 & \\
\hline & & & 1000 & 9.4 & \\
\hline & & & 800 & 11.2 & \\
\hline & & & 850 & 10.7 & \\
\hline \multirow[t]{3}{*}{ Combustion (21\%) } & Air & 500 & 900 & 10.2 & 2 \\
\hline & & & 950 & 9.8 & \\
\hline & & & 1000 & 9.4 & \\
\hline
\end{tabular}




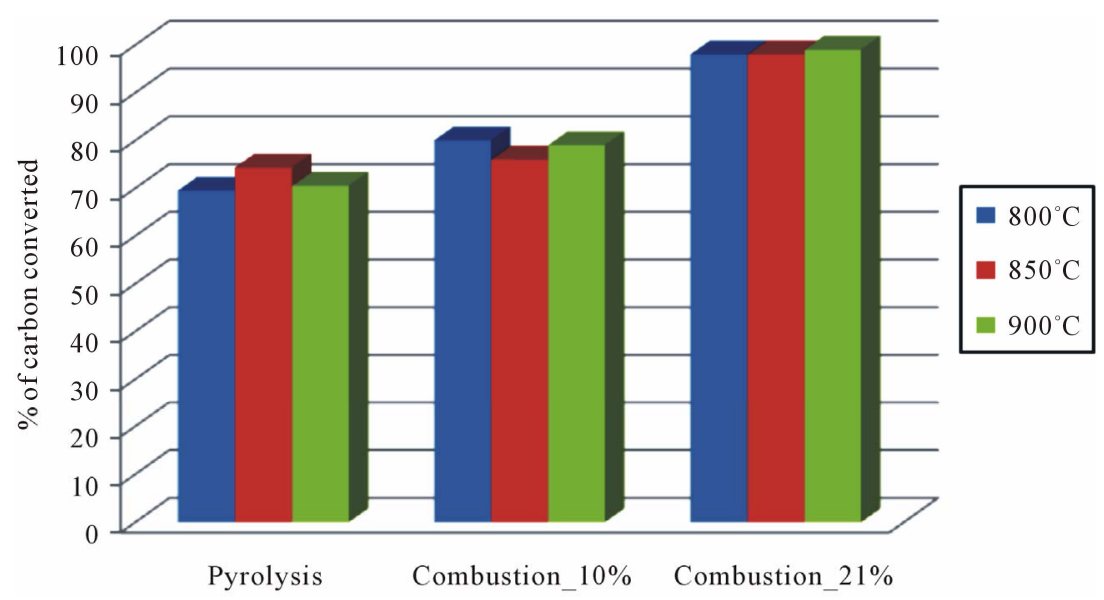

Figure 2. Conversion rate of carbon at different temperatures during the thermal degradation of polyethylene plastic bags.

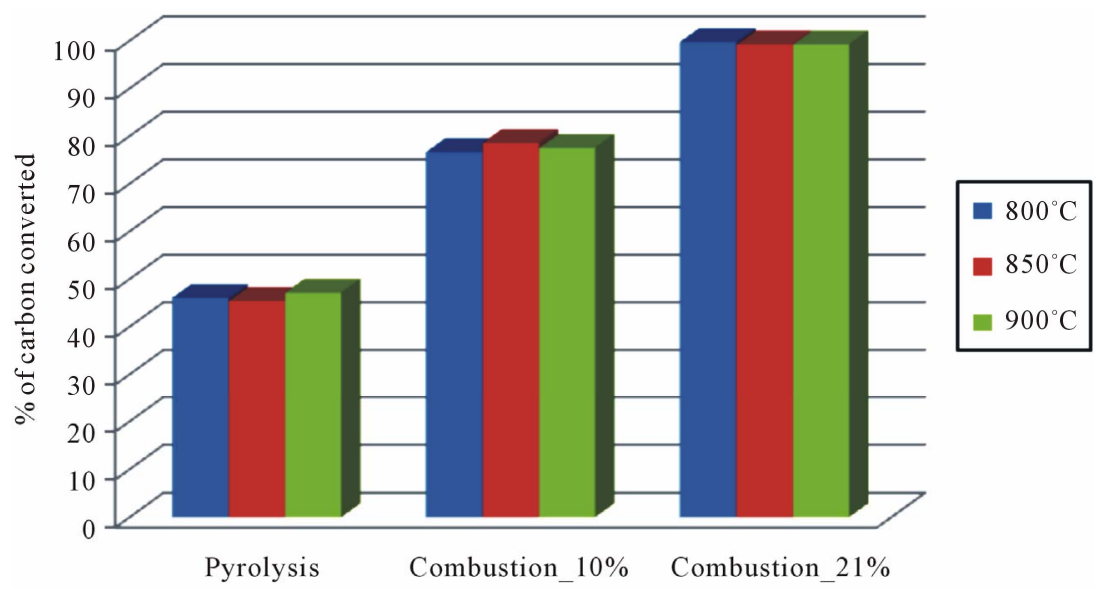

Figure 3. Conversion rate of carbon at different temperatures during the thermal degradation of millet stalks.

$\mathrm{C}-\mathrm{H}$ while it is still insufficient to break the aromatic rings of the components of millet stalks.

When observing the conversion efficiency for an oxidant combustion (plastic bags and millet stalks), there are $98 \%$ to $99 \%$ of volatile carbon in the form of carbonaceous compounds analyzed. These efficiencies allow us to assume that $1 \%$ to $2 \%$ of carbon not analyzed is in the form of aromatic compounds that are found most often in the soot and/or tar from these combustion system. Moreover, whatever the temperature, the overall efficiency of carbon conversion increases linearly with the local oxygen concentration. The average rate of carbon conversion for plastic bags is:

- $71.4 \%$ during the pyrolysis;

- $78.3 \%$ for reductive combustion with $10 \%$ oxygen;

- $98.3 \%$ for oxidant combustion.

The millet stalks:

- $46 \%$ during the pyrolysis;

- $77.5 \%$ for reductive combustion with $10 \%$ oxygen;

- $99.3 \%$ for the oxidant combustion.

Regarding the thermal degradation of plastic bags, we see that the reducer environment has fostered the conversion of $7 \%$ of more carbon while the presence of oxygen in double proportion promotes the conversion of $27 \%$ of carbon. In reducer conditions, we have collected, in addition to ash, a residue in which unconverted carbon is probably. On the other hand, in an oxidant atmosphere, the local concentration of oxygen is sufficient to burn everything and leaving only ashes.

\subsection{Carbon Conversion: Influence of the Local Content of Oxygen}

It is, in this part, to make a comparative study of the conversion rate of carbon depending on the local oxygen content, for different temperatures tested. The objective is to verify the consistency of results and observe the reactional intermediates involved primarily in the process of formation of nitrogen monoxide (CO) and carbon dioxide $\left(\mathrm{CO}_{2}\right)$.

\subsubsection{Plastic Bags}

Figures 4-8 represent the rate of carbon converted 
$800^{\circ} \mathrm{C}$

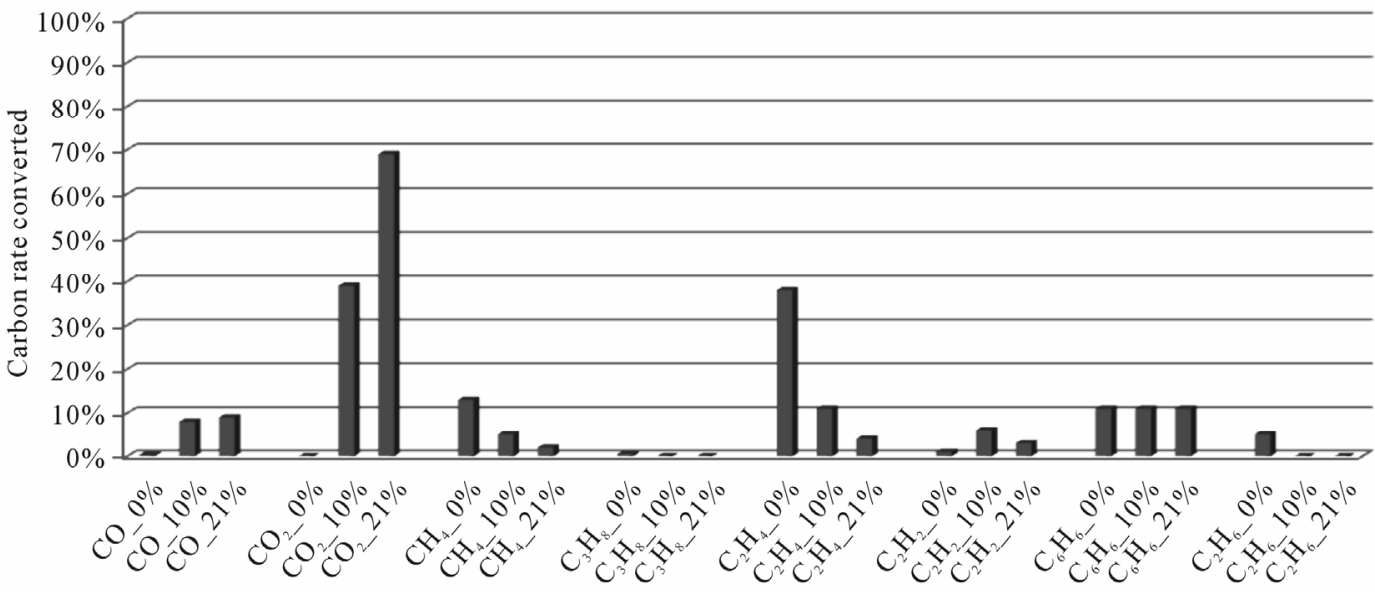

Figure 4. Evolution of the conversion rate of carbon for each compound detected according to the local oxygen content at $800^{\circ} \mathrm{C}$, for plastic bags.

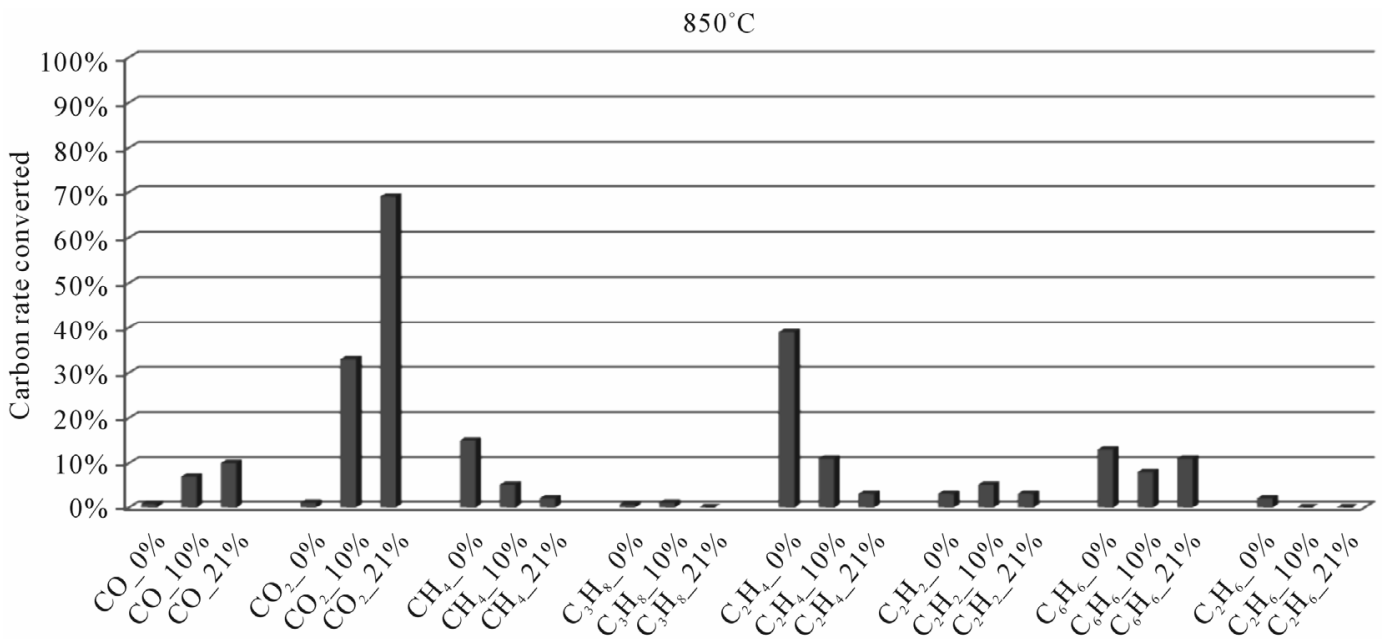

Figure 5. Evolution of the conversion rate of carbon for each compound detected according to the local oxygen content at $850^{\circ} \mathrm{C}$, for plastic bags.

$900^{\circ} \mathrm{C}$

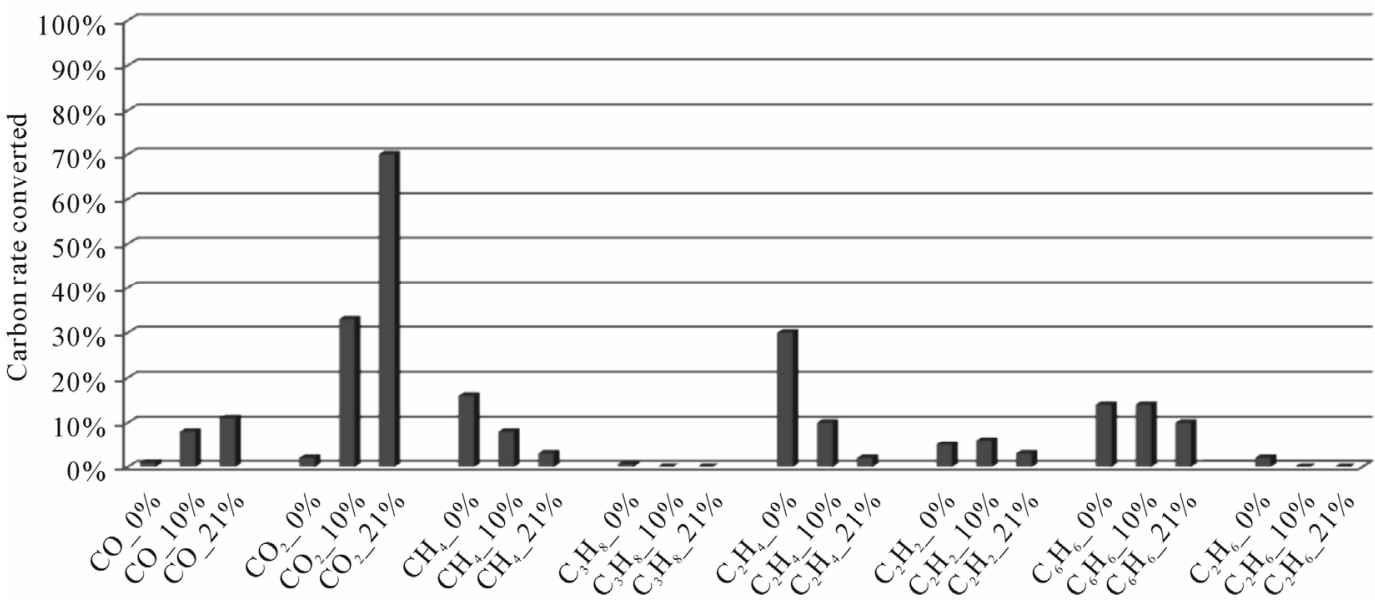

Figure 6. Evolution of the conversion rate of carbon for each compound detected according to the local oxygen content at $900^{\circ} \mathrm{C}$, for plastic bags. 


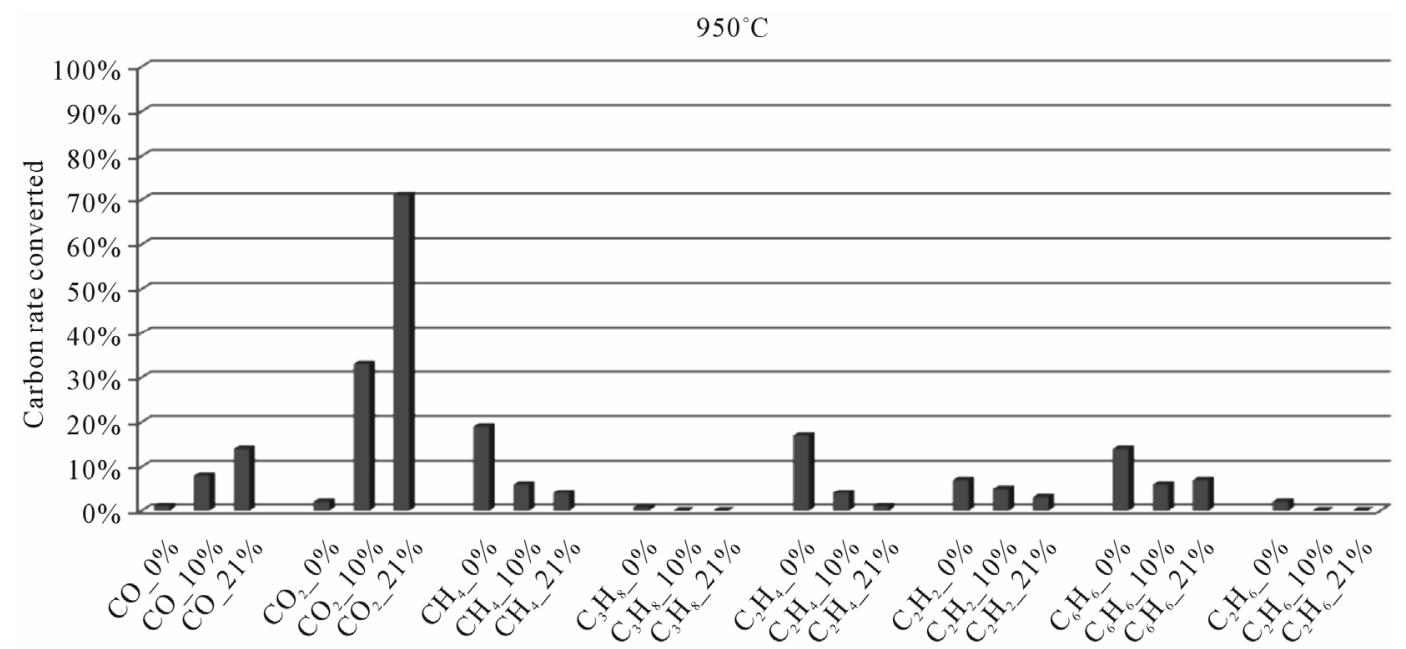

Figure 7. Evolution of the conversion rate of carbon for each compound detected according to the local oxygen content at $950^{\circ} \mathrm{C}$, for plastic bags.
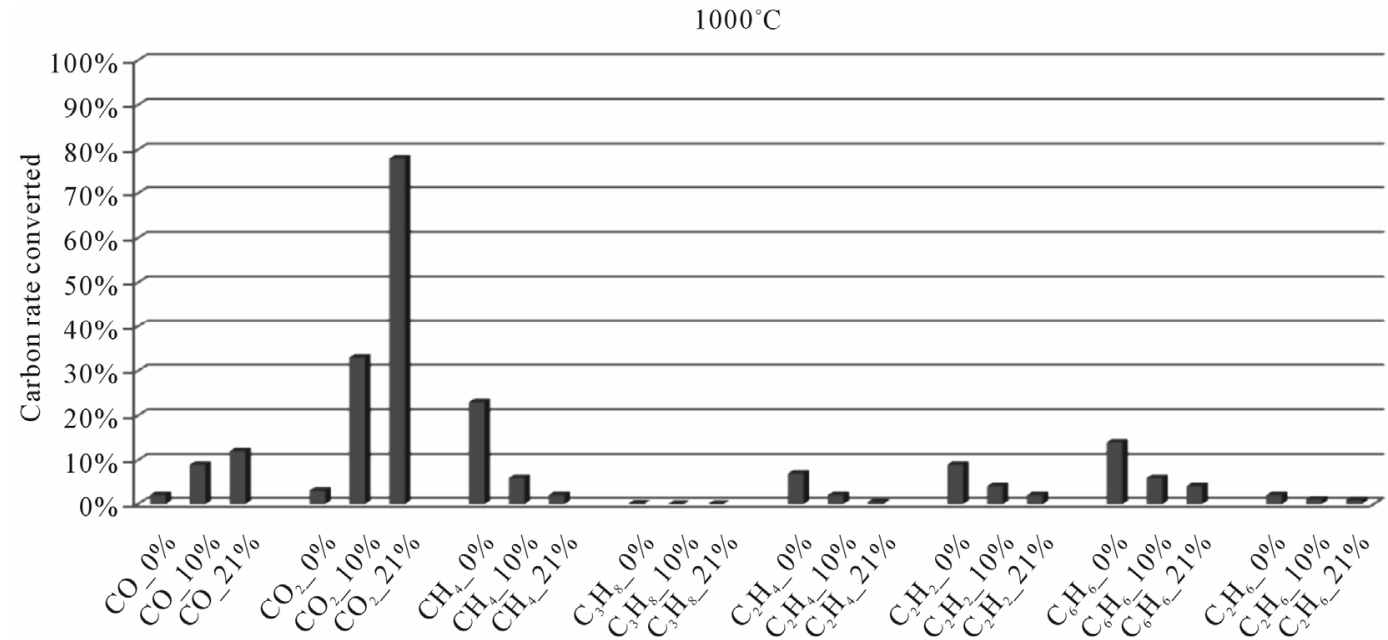

Figure 8. Evolution of the conversion rate of carbon for each compound detected according to the local oxygen content at $1000^{\circ} \mathrm{C}$, for plastic bags.

according to the local content of oxygen for carbon oxides and hydrocarbons analyzed during the thermal degradation of plastic bags. These histograms are presented for each temperature tested.

When we see Figures 4-8, we find that:

1) The rate of carbon converted into $\mathrm{CO}$ and $\mathrm{CO}_{2}$ increases when the local oxygen content increases. Regarding the production of $\mathrm{CO}$, the result can be explained by the fact that oxygen comes mainly from the air oxidant: Indeed, the elementary chemical analysis revealed the presence of a small amount of oxygen in polyethylene bags (4.8\%). In such a situation, there is a tendency to promote the oxidation reactions of $\mathrm{CO}$ into $\mathrm{CO}_{2}$ for the benefit of those of hydrocarbons into CO.

2) When the oxygen rate increases, we find a decreasing rate of carbon converted into methane $\left(\mathrm{CH}_{4}\right)$ and ethylene $\left(\mathrm{C}_{2} \mathrm{H}_{4}\right)$. This suggests to us that during the thermal degradation of plastic bags, the formation of $\mathrm{CO}$ and $\mathrm{CO}_{2}$ by oxidation of light hydrocarbons comes primarily from gaseous compounds $\mathrm{CH}_{4}$ and $\mathrm{C}_{2} \mathrm{H}_{4}$. These assumptions are confirmed by the literature. Indeed, during their studies on the oxidation of hydrocarbons $\left(\mathrm{CH}_{4}, \mathrm{C}_{2} \mathrm{H}_{4}\right)$ in the presence of $\mathrm{NO}$, for different temperatures and oxygen concentrations, [28] highlight the different pathways of $\mathrm{CO}$ formation. They show that the formation of $\mathrm{CO}$ from $\mathrm{CH}_{4}$ is an increasing function of temperature. This formation begins at a temperature of $560^{\circ} \mathrm{C}$. But when the temperature rises above $630^{\circ} \mathrm{C}$, there is a reduction in the amount of $\mathrm{CO}$ due to oxidation of $\mathrm{CO}$ into $\mathrm{CO}_{2}$. Thus, at $670^{\circ} \mathrm{C}$, all the $\mathrm{CH}_{4}$ is oxidized into $\mathrm{CO}$ and $\mathrm{CO}_{2}$, for a mixture of " $\mathrm{CH}_{4}-\mathrm{NO}$ " with $5 \%$ oxygen. [17] also show that the ethylenic compounds will lead to the formation of $\mathrm{CO}$ and $\mathrm{CO}_{2}$, above $730^{\circ} \mathrm{C}$.

3) At $950^{\circ} \mathrm{C}$, in addition to $\mathrm{CH}_{4}$ and $\mathrm{C}_{2} \mathrm{H}_{4}$, we have also 
acetylene $\left(\mathrm{C}_{2} \mathrm{H}_{2}\right)$ which is involved in the production of carbon oxides. This is certainly due to the increase in temperature which produces an energy to break the triple bond of $\mathrm{C}_{2} \mathrm{H}_{2}$.

4) At $1000^{\circ} \mathrm{C}$, as well as $\mathrm{CH}_{4}, \mathrm{C}_{2} \mathrm{H}_{4}$ and $\mathrm{C}_{2} \mathrm{H}_{2}$, benzene $\left(\mathrm{C}_{6} \mathrm{H}_{6}\right)$ is heavily involved in the formation of $\mathrm{CO}$ and $\mathrm{CO}_{2}$. At this temperature, energy reached is sufficiently important to break the aromatic ring of benzene and the double bonds.

\subsubsection{Millet Stalks}

In the histograms 9 to 13 , the rate of carbon converted according to the local content of oxygen for carbon oxides and hydrocarbons analyzed during the thermal degradation of millet stalks, is presented. These figures are shown for each temperature tested.

When we look at Figures 9-13, we find that:
1) The rate of carbon converted into $\mathrm{CO}$ decreases when oxygen increase, while the opposite phenomenon occurs with the carbon detected in $\mathrm{CO}_{2}$. This confirms a logical fact since more oxygen increases more combustion is better, that is to say that the oxidation reactions producing $\mathrm{CO}_{2}$ are faster than the oxidation reactions of hydrocarbons into CO.

2) When we makes a comparison by type of thermal degradation (pyrolysis, combustion at 10\% oxygen, combustion with $21 \%$ oxygen) between the millet stalks and plastic bags, we see that in the same experimental conditions, the rate of carbon converted into $\mathrm{CO}$ and $\mathrm{CO}_{2}$ is millet stalks than for plastic bags. Indeed, the elementary chemical composition of the two fuels shows that oxygen rate is much higher in millet stalks (43.8\%) than in polyethylene plastic bags (4.8\%). We believe this difference affects the rate of carbon converted into carbon oxides

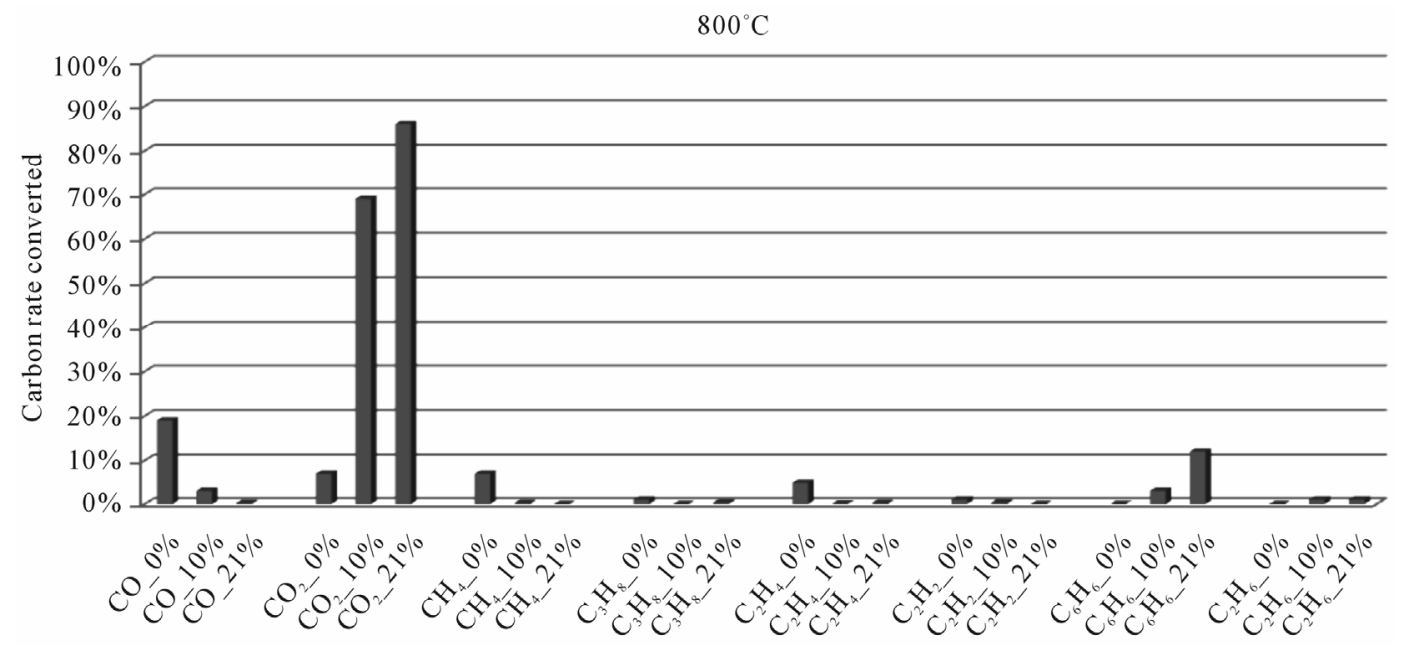

Figure 9. Evolution of the conversion rate of carbon for each compound detected according to the local oxygen content at $800^{\circ} \mathrm{C}$, for millet stalks.

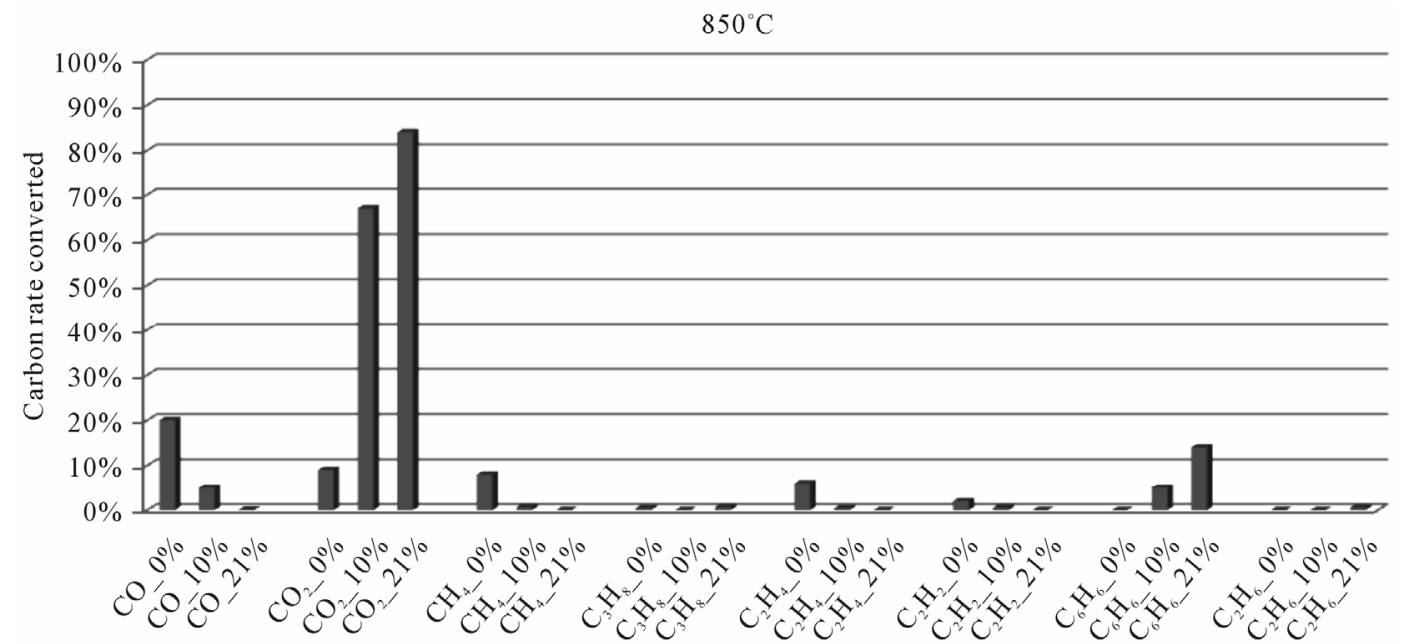

Figure 10. Evolution of the conversion rate of carbon for each compound detected according to the local oxygen content at $850^{\circ} \mathrm{C}$, for millet stalks. 
$900^{\circ} \mathrm{C}$

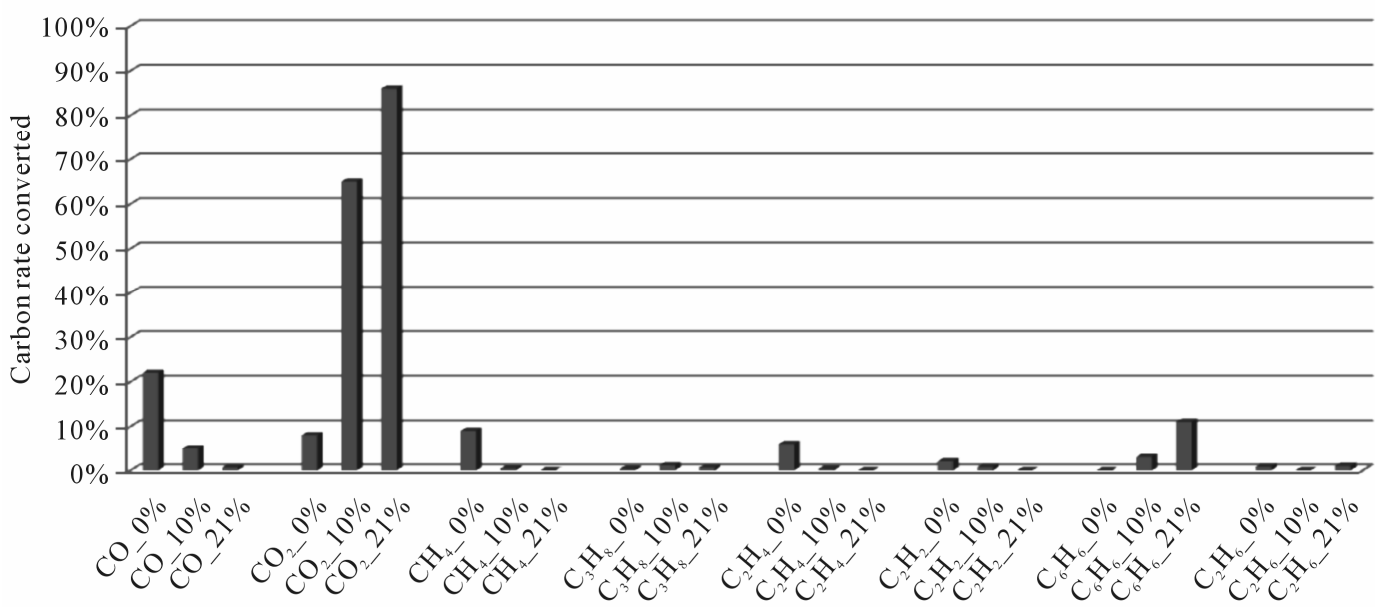

Figure 11. Evolution of the conversion rate of carbon for each compound detected according to the local oxygen content at $900^{\circ} \mathrm{C}$, for millet stalks.

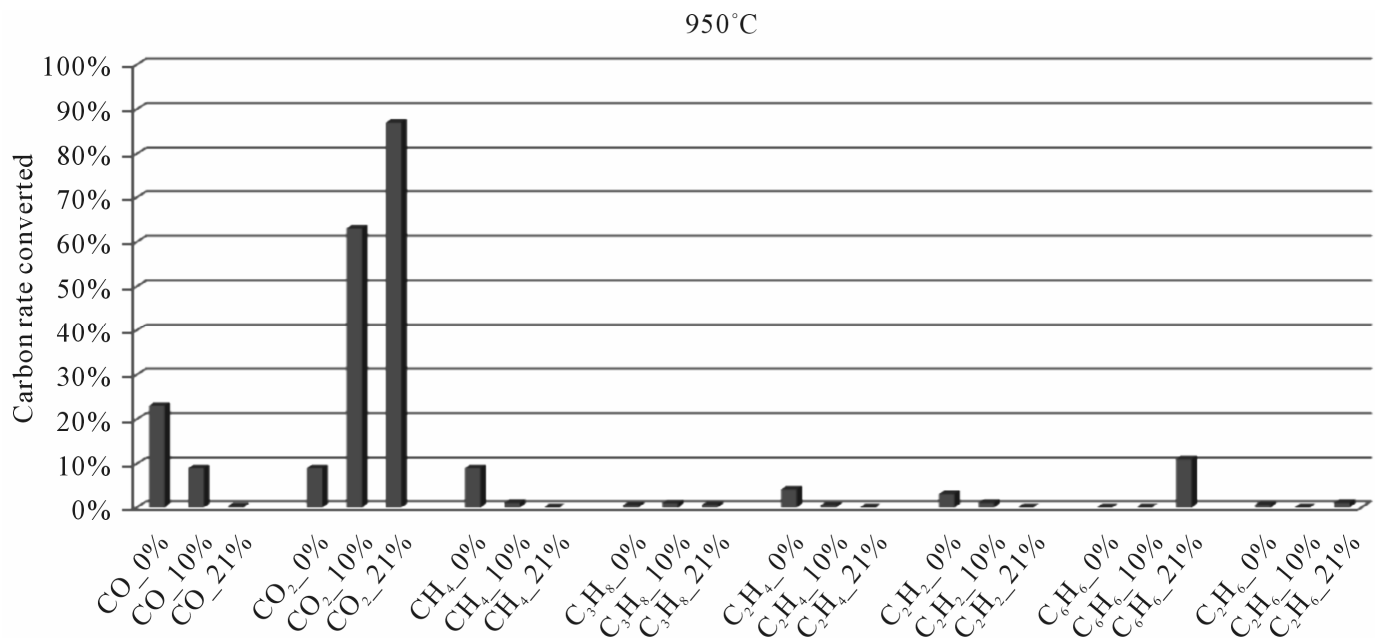

Figure 12. Evolution of the conversion rate of carbon for each compound detected according to the local oxygen content at $950^{\circ} \mathrm{C}$, for millet stalks.

$1000^{\circ} \mathrm{C}$

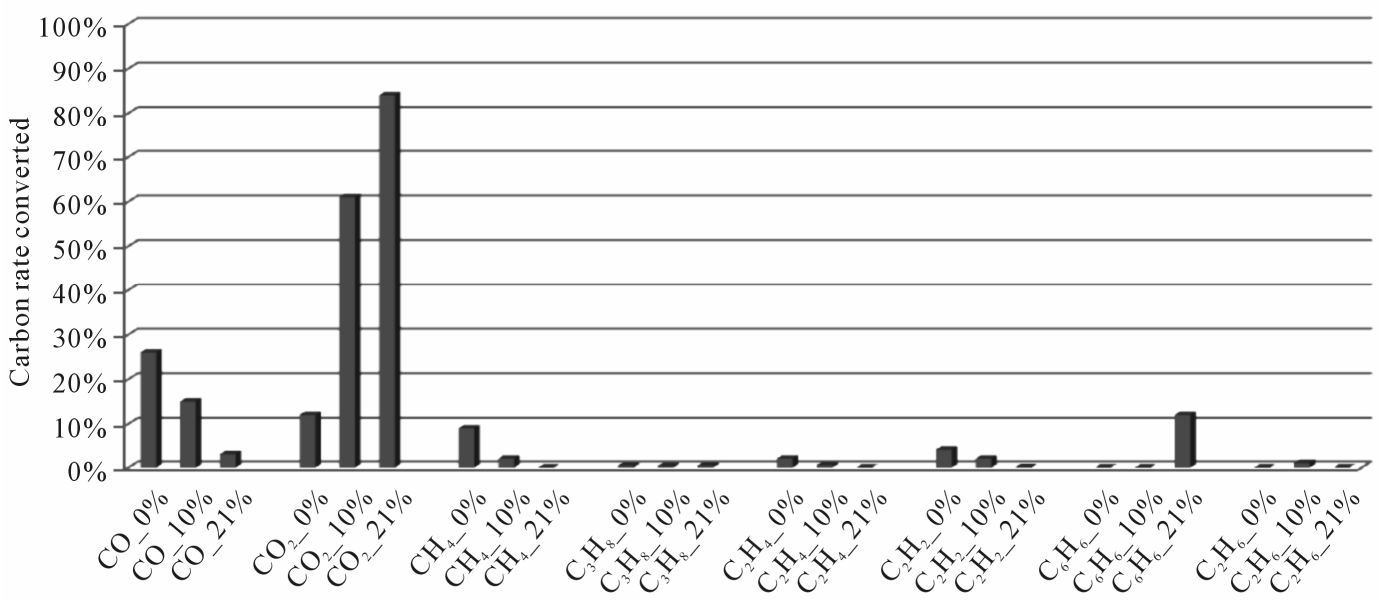

Figure 13. Evolution of the conversion rate of carbon for each compound detected according to the local oxygen content at $1000^{\circ} \mathrm{C}$, for millet stalks. 
during the pyrolysis. Similarly, for the millet stalks, we note that going from pyrolysis to combustion (at 10\% and $21 \%$ oxygen), there is practically no hydrocarbons emitted. This same difference can also explain the fact that the oxygen present in the millet stalk and oxygen from the air allow substantially all hydrocarbons to become oxidized in CO.

\section{Conclusions}

This work was used to study the potential influence of temperature and local oxygen concentration on the conversion efficiency of carbon into $\mathrm{CO}, \mathrm{CO}_{2}, \mathrm{CH}_{4}, \mathrm{C}_{3} \mathrm{H}_{8}$, $\mathrm{C}_{2} \mathrm{H}_{4}, \mathrm{C}_{2} \mathrm{H}_{2}, \mathrm{C}_{2} \mathrm{H}_{6}, \mathrm{C}_{6} \mathrm{H}_{6}$, during thermal degradation of millet stalks and plastic bags. The experimental device used is the tubular furnace, coupled to the analyzer Fourier Transform Infrared (FTIR) and a Non Dispersive Infrared analyzer (NDIR).

The results obtained on the influence of temperature allow to see that for each type of thermal degradation and whatever the temperature of the combustion, the conversion rate of carbon remains substantially the same.

- In the case of plastic bags, the rate of carbon converted during pyrolysis is about $90 \%$ of carbon converted during reductive combustion. On the other hand, with millet stalks, the carbon converted represents only $60 \%$ of the rate of carbon converted during combustion to $10 \%$ oxygen. $1 \%$ to $2 \%$ of carbon not analyzed is in the form of aromatic compounds that are found most often in the soot and/or tar which come from these combustion systems. Moreover, whatever the temperature, the overall efficiency of carbon conversion increases linearly with the local concentration of oxygen.

- During the thermal degradation of plastic bags, we see that the reducer environment has fostered the conversion of $7 \%$ of more carbon while the presence of oxygen in double proportion promotes the conversion of $27 \%$ carbon.

Regarding the influence of the oxygen, it is clear that:

\section{- Plastic bags}

The reactions of oxidation of $\mathrm{CO}$ into $\mathrm{CO}_{2}$ tend to be favored for the benefit of those of hydrocarbons into CO. The formation of $\mathrm{CO}$ and $\mathrm{CO}_{2}$ by oxidation of light hydrocarbons primarily comes from gaseous compounds $\mathrm{CH}_{4}$ and $\mathrm{C}_{2} \mathrm{H}_{4}$. At $950^{\circ} \mathrm{C}$, we have also acetylene $\left(\mathrm{C}_{2} \mathrm{H}_{2}\right)$ which is involved in the production of carbon oxides. At $1000^{\circ} \mathrm{C}$, benzene $\left(\mathrm{C}_{6} \mathrm{H}_{6}\right)$ is also heavily involved in the formation of $\mathrm{CO}$ and $\mathrm{CO}_{2}$.

\section{- Millet stalks}

More oxygen increases more combustion is better, that is to say that the oxidation reactions producing $\mathrm{CO}_{2}$ are faster than the oxidation reactions of hydrocarbons into CO. Similarly, for the millet stalks, in passing the pyro- lysis to combustion (at $10 \%$ and $21 \%$ oxygen), there is practically no hydrocarbons emitted. The rate of carbon converted into $\mathrm{CO}$ and $\mathrm{CO}_{2}$ is higher for millet stalks than for plastic bags, due to the oxygen rate higher in millet stalks than in plastic bags.

In conclusion, we say that the temperature and the local oxygen concentration are parameters strongly influencing the formation and reduction of oxides carbon during the thermal degradation of plastic bags and millet stalks.

In future work, it would be interesting for the same experience and local concentrations of oxygen of $5 \%$ and $15 \%$, to know the influence of the local concentration of oxygen on the rate of conversion of carbon and nitrogen. This could confirm the results we obtained in this article. Also do a study to lower temperatures $\left(350^{\circ} \mathrm{C}\right.$ to $\left.750^{\circ} \mathrm{C}\right)$ would allow us to be more precise on hydrocarbons mainly involved in the formation of carbon oxides. These results coupled with a thermo-gravimetric analysis (under the same conditions) will result in the establishment of reaction mechanisms of formation and reduction of carbon oxides during the combustion of materials such as biomass and plastics based on polyethylene.

\section{REFERENCES}

[1] T. Rogaume, M. Auzanneau, F. Jabouille, J. C. Goudeau and J. L. Torero, "The Effects of Different Airflows on the Formation of Pollutants during Waste Incineration," Fuel, Vol. 81, No. 17, 2002, pp. 2277-2288. doi:10.1016/S0016-2361(02)00151-5

[2] T. Rogaume, M. Auzanneau, F. Jabouille, J. C. Goudeau and J. L. Torero, "Computational Model to Investigate the Effect of Different Airflows on the Formation of Pollutants during Waste Incineration," Combustion Science and Technology, Vol. 175, No. 8, 2003, pp. 1501-1533. doi:10.1080/00102200302355

[3] T. Rogaume, F. Richard, F. Jabouille and J. L. Torero, "Computational Model to Investigate the Mechanisms of NOx Formation during Waste Incineration,” Combustion Science and Technology, Vol. 176, No. 5-6, 2004, pp. 925-943. doi:10.1080/00102200490428549

[4] F. Richard, T. Rogaume, A. T. Barhe, S. K. Ouiminga, J. L. Torero and P. Rousseaux, "Influence of the Regime of Combustion on Chemical Pathways of NOx Formation during Incineration of Cellulosic and Plastic Materials," Mediteranean Symposium on Combustion, Monastir, 9-13 September 2007.

[5] P. Tice, "Polyethylene for Food Packaging Applications," Report Prepared under Responsibility of the ILSI Europe Packaging Material Task Force, 2003.

[6] Z. Wang, J. Wang, H. Richter, J. B. Howard, J. Carlson and A. Y. Levendis, "Comparative Study on Polycyclic Aromatic Hydrocarbons, Light Hydrocarbons, Carbon Monoxide, and Particulate Emissions from the Combustion of Polyethylene, Polystyrene and Poly(Vinyl Chloride,” Energy \& Fuels, Vol. 17, No. 4, 2003, pp. 999- 


\section{3. doi:10.1021/ef020269z}

[7] L. Wheatley, Y. A. Levendis and P. Vouross, "Exploratory Study on the Combustion and PAH Emission of Selected Municipal Waste Plastics,” Environmental Science Technology, Vol. 27, No. 13, 1993, pp. 2885-2895. doi:10.1021/es00049a032

[8] C. H. Wu, C. Y. Chang, J. L. Hor, S. M. Shih, L. W. Chen and F. W. Chang, "On the Thermal Treatment of Plastic Mixtures of MSW: Pyrolysis Kinetics," Waste Management, Vol. 93, No. 3, 1993, p. 221.

[9] O. Beaumont, “Burning Wood,” Biomass News, No. 17, 1985.

[10] R. Dumont and M. Gelus, "Valuation Chemical Wood," Preparation of Firewood, Chapter 3, 1982.

[11] F. Jabouille, "Contribution to the Study of Emission Factors for Nitrogen Oxides during the Incineration of Household Waste,” Ph.D. Thesis, University of Poitiers, Poitiers, 1996.

[12] F. Jabouille, X. Zhou, B. Bregeon and J.-C. Goudeau, "Limitation of Emissions of NOx: Experimental Driver for Municipal Waste Incinerator," Waste Science and Technology, No. 2, 1996, pp. 20-25.

[13] Y. Rogaume, F. Jabouille, J.-C. Pirault, G. Bregeon,
"Minimization of NOx Emissions in Waste Incineration Process," Proceedings of 4th Annual Symposium on Environmental Issues and Wastewater Management in Energy and Mineral Production, SWEMP 96, Cagliari, 7-11 October 1996.

[14] Y. Rogaume, "Physical Chemistry of the Thermal Degradation of Molecules Containing Nitrogen: Case of Polyamide and Polyurethane,” Ph.D. Thesis, University of Poitiers, Poitiers, 1999.

[15] J. Tezanou, "Environmental and Technical Assessment of the Management of Household Waste in Ouagadougou: Management Schemes and Experimental Heat Treatment," Ph.D. Thesis, University of Poitiers, Poitiers, 2003.

[16] A. T. Barhe, "Erimental and Numerical Study of the Influence of Process Parameters on the Mechanisms of Formation of Nitrogen Oxides during the Combustion of Mixtures of Cellulosic and Plastic Materials,” Ph.D. Thesis, University of Poitiers, Poitiers, 2004.

[17] T. Faravelli, A. Frassoldati and E. Ranzi, "Kinetic Modeling of the Interactions between NO and Hydrocarbons in the Oxidation of Hydrocarbons at the Low Temperatures," Combustion and Flame, Vol. 132, 2003, pp. 188207. doi:10.1016/S0010-2180(02)00437-6 